\title{
Building Dynamic Capabilities for High Margin Product Development: \\ A Corporate Control Style Perspective.
}

\section{Myropi Garri ${ }^{1}$, Lee Spicer ${ }^{2}$, Vijay Pereira ${ }^{3}$, Shlomo Tarba ${ }^{4}$, Yama Temouri $^{5}$, Ashish Malik ${ }^{6}$}

1. Senior Lecturer, Strategy Enterprise Innovation SG, Faculty of Business and Law, University of Portsmouth, Portsmouth UK

2. MBA, University of Portsmouth, Distinct Strategy Founder, Southampton UK

3. Associate Professor, International and Strategic HRM, University of Wollongong in Dubai, Dubai, UAE

4. Associate Professor, Department of Strategy and International Business, University of Birmingham, Birmingham, UK

5. Associate Professor at University of Wollongong in Dubai

University of Wollongong in Dubai, UAE

6. Senior Lecturer, Newcastle Business School, University of Newcastle, Callaghan, Australia

\begin{abstract}
This paper contributes to the dynamic capabilities (DCs) literature by delving into the relationship between DCs, corporate control style (CCS), and high margin product development (HMPD)-company performance. Our qualitative results are based on semi-structured interviews conducted within a multinational telecommunication corporation. The narratives indicate that DCs positively influence HMPD/company performance. The level of positive influence of DCs on performance will depend on the CCS of the organization, since CCS directly affects the seizing and transforming activities of DCs. CCS also regulates the link between sensing and shaping DCs activities and HMPD/performance. We find evidence that there is no specific order in which the sensing, seizing, and transforming activities occur. We suggest that the identification of "Surge" and "Lurch" events is a key channel for managers to enhance DCs management in their organisation. Our findings are compared to relevant studies on EMNEs.
\end{abstract}

Keywords: Dynamic Capabilities, High Margin Product Development, Corporate Control Style, Surge and Lurch Events, Environmental Velocity 


\section{Introduction:}

The dynamic capabilities (DCs) perspective (Teece \& Pisano, 1994) is increasingly prevalent within management research (Felin and Powel, 2016). The DCs literature identifies the foundations of long-term company growth, and illustrates how and why companies gain and sustain competitive advantage under conditions of rapid change (Teece \& Augier, 2007). However, Zahra et al (2006) note that it is difficult to differentiate between the existence of DCs and its effects. Although several researchers monitor a positive relationship between DCs and company performance (e.g., Eisenhardt and Martin, 2000; Stadler et al, 2013), others report insignificant effects (Zott, 2003), or even negative ones (e.g., Wilden and Gudergan, 2014; Pezeshkan et al, 2016). Therefore, it is important to continue collecting evidence in order to clarify the consequences of DCs (Fainshmidt et al, 2016). Some disagreement also exists on the nature of the link between DCs and performance (Ambrosini and Bowman, 2009). Primary work on mechanisms has assumed the link to be direct (e.g., Teece and Pisano, 1994). Lately, however, it has been illustrated as being indirect, implying that DCs affect performance through the unique resource and capability configurations they develop (e.g., Zollo and Winter, 2002). We add to the debate by exploring the following research question: what is the nature of the link between DCs and performance, and are there other influences that can account for the outcome of this link? We add to DCs theory by bringing evidence on the nature of the link between DCs and performance. We contribute to this debate by unravelling both direct and indirect regulating influences on DCs and on their link to company performance.

Innovation (Doving and Gooderham, 2008; Lee et al, 2011) and radical dynamization (Eisenhardt and Martin, 2000; Helfat et al, 2009) are two of the approaches that explain the link between DCs and performance (Schreyögg and Kliesch-Eber, 2007). The dynamic environment is driving companies to concentrate on innovation activities (Eisenhardt and Martin, 2000). The innovation approach describes DCs as problem-solving patterns and organizational processes that involve a specific pattern of activity and learning through organizational cooperation (Doving and Gooderham, 2008; Lee et al, 2011; Malik and Nilakant, 2015). The research on the innovation approach of DCs has been expanded to incorporate new product development (King and Tucci, 2002; Majumdar, 2000). Eisenhardt and Martin (2000) interrelate product innovation and DCs, as both are linked to the renewal and 
reconfiguration of a company's resources. Considering the sensing-seizingtransforming triplet, this perspective seems to limit the link between product development and DCs to transformation activities only. The above leads to the following question: to which aspects of DCs is product innovation/ development linked? Is it linked only to DCs transformation activities, or is it also linked to sensing and seizing? Notably, the DCs literature is still limited in terms of empirical studies linking product innovation and DCs, particularly of those containing longitudinal and qualitative data (Breznik \& Lahovnik, 2016). This paper aims to contribute to the innovation approach (Doving and Gooderham, 2008; Lee et al, 2011) to DCs by exploring the link between DCs and performance. We measure performance as the development of commercially successful high margin products-i.e., products that provide marginal returns above the $80^{\text {th }}$ percentile - as these have been proven to improve company revenue, market share, market value, and survival (Katila and Ahuja, 2002). Specifically, looking at the case of a large MNE operating in a high-velocity environment, we explore the link between high margin product development (HMPD) and the sensing-seizing-transforming tripartite of DCs. At the same time, addressing the call made by Easterby-Smith et al (2009), we examine the development of DCs and their effect over time by exploring the company's long history of HMPD.

Researchers have focused on the examination of DCs' processes, antecedents, and outcomes (Erikson et al, 2014). Teece (2007) discusses the antecedents of DCs by analysing the micro-foundations of DCs development. He notes that sensing relates to specific capacities and organisational processes connected to uncovering opportunities. The antecedents of seizing mirror the choice of product architectures and business models, organisational boundaries, decision-making protocols, and the building of loyalty among employees. The antecedents of transforming concern decentralisation, co-specialisation, organizational structure, and knowledge management (Erikson et al, 2014). Interestingly, there is no significant evidence on the effect of corporate governance-related issues, such as corporate control style (CCS) at the corporate level towards the development of DCs at the business level (Breznik et al, 2016, Eriksson et al 2014). Corporate control style is associated with the ways in which a company manages a set of businesses together (Grant, 1995). CCS includes the composition of businesses; resource allocation (planning and control); formulation of business unit strategies (planning and control, corporate management); control of business unit performance (planning and control); and coordination of business units and creation of 
company cohesiveness and direction (core competencies, organizational structure, organizational climate, corporate management) (Grant, 1995: 396-397). The notion of CCS requires businesses to achieve direction, coordination, and commitment at several levels, such as between managers (Adner and Helfat, 2003) and top management teams (TMTs) (Li et al, 2008). It is important to look at the connection between DCs and CCS, as CCS will affect most of the above recognized antecedents of DCs. In order to fill the above gap, this paper attempts to answer the following question: what is the effect of CCS influence on the development of DCs, and what is the effect of CCS on the relationship between DCs and HMPD (performance)? We add to the debate on the antecedents and micro-foundations of DCs by interconnecting CCS to the mechanisms of DCs and to their performance outcomes. The understanding of the association between CCS and DCs, and of their effect on HMPD will provide valuable insights into how differentiation through product development can be achieved at the corporate and business levels to serve the company's long term growth goals.

Apart from the antecedents, which are internal to an organisation, it is expected that external factors - such as the pace of industry changes (Ambrosini and Bowman, 2009) - may also act as enablers (or inhibitors) of DCs. The theoretical foundation of external DCs antecedents can be found in the radical dynamization approach (Eisenhardt and Martin, 2000), which separates between moderately dynamic and highvelocity markets and advocates a contingency relationship between DCs and market dynamism to explain the differentiation among dissimilar degrees and patterns of DCs (Eisenhardt and Martin, 2000; Helfat et al, 2009). However, as the rate of change fluctuates even in high-velocity environments, we pose the following question: what is the effect of rapid positive or negative changes in environmental velocity on the development of DCs in high-velocity environments? Evaluating DCs theory, Williamson (1999) emphasizes the need to specify when a company should reconfigure its capabilities. We add to the debate on the antecedents and micro-foundations of DCs by looking at sudden positive and negative changes in the external environmentnamed 'surge' and 'lurch' events respectively_as an indicator for the management of DCs.

DCs research should identify and evaluate the similarities and differences between EMNEs and MNEs from developed markets in DCs building activities, antecedents, and outcomes, as this would enrich DCs theory (Williamson, 2015). In this 
paper, we compare and contrast our results, drawn from a MNE from a developed market, with previous similar research carried out in EMNEs.

This paper analyses the case of a large MNE. The analysis is based on the Telecom SBU. The next section of the paper reviews the theoretical background surrounding the interaction between DCs, CCS and HMPD in high-velocity environments. The paper then outlines the research methods and provides the findings of the qualitative study. Finally, the paper discusses the findings and concludes with the implications for theory and practice.

\section{Literature Review}

Dynamic capabilities (Teece \& Pisano, 1994) offer a context in which companies may continually adjust their resources to create sustainable competitive advantage (Eisenhardt \& Martin, 2000). Although the connection between DCs and company performance has been questioned by some researchers (e.g., Wilden and Gudergan, 2014), and the moderating effect of technological dynamism on the above relationship has been doubted (Fainshmidt et al, 2016), significant evidence supports the explanatory ability of the DCs framework (Pezeshkan et al, 2016).

New product development capabilities have been particularly related to enhanced company performance (Wang and Ahmed, 2007). Persistent high performance in high-velocity environments is driven by a succession of temporary advantages from new product developments (Eisenhardt \& Martin, 2000). Considering HMPD as a DC (Eisenhardt \& Martin, 2000) allows an empirical analysis of the organization's performance through time. Innovation and asset allocation lie at the heart of DCs (Teece, 2007). Although innovation by itself is insufficient to generate success (Teece, 1986), as a capability, it is cumulative and endogenous (Teece, 2007), and investment in new technology is critical to long term success (Chandler, 1962). Clearly, superior performance and risk mitigation require the organisation to have the ability to innovate, making it necessary for management to have the capacity to refocus priorities and reallocate resources (Nonaka \& Teece, 2001). However, the company may determine the optimal allocation of resources according to its CCS (Goold \& Campbell, 1987). Many factors that are key to DCs are shared with CCS, suggesting interdependency. For instance, decentralised organisations are more likely to mitigate 
the risk of unforeseen technological or market developments (Teece et al, 1997). However, they can miss core and periphery opportunities arising from customers, suppliers, and complementors (Teece, 2009). In contrast, centralisation may lead to management decisions that are isolated from realities; thus the decentralisation of R\&D activities tends to be favoured (Teece, 2007). Corporations that control multiple SBU's tend to develop bureaucratic features that muzzle innovation through slow decision making and the preservation of the status quo. Decision makers have the ability to starve new business of financial capital (Teece, 2007). This paper intends to investigate the relationships between these concepts.

\subsection{The effect of DCs Development on company performance - High Margin Product Development}

Talking about the nature of DCs, Eisenhardt and Martin (2000) see them as particular and recognizable processes that may integrate or reconfigure resources. Product development is noted as an example (Erikson et al, 2014), as both DCs and product innovation are linked to the renewal and reconfiguration of a company's resources. Indeed, DCs can be identified within strategic decisions and processes for product development (Eisenhardt \& Martin, 2000) and innovation (Katila and Ahuja, 2002) as "the more innovative a company is, the more it possesses DC" (Wang and Ahmed, 2007: 8). Innovation can be complex and may require the contributions of individuals across business, hierarchical, and geographical boundaries (Michailova \& Zhan, 2014). Uncertainty is ubiquitous with innovation (Teece et al, 2016). The greater the uncertainty and dynamism of the business environment and the greater the need for organizational agility, the more good strategy, entrepreneurial management, and strong DCs become critical for company performance (Teece et al, 2016). Considering the sensing-seizing-transforming triplet, this perspective seems to limit the link between product development and DCs to transformation activities only.

Dynamic Capabilities can be considered as the organisation's ability to sense changes and opportunities in the external environment and to effectively redeploy resources to seize them (Teece, 2007). DCs must be in harmony with the strategic direction of the company, thus allowing the exploitation of emergent opportunities (Teece et al, 2016). DCs are identified as processes (Ambrosini and Bowman, 2009), or as comprising processes (Teece et al., 1997). Theserocesses are structured as echelons including both organisational and managerial processes designed for the 
identification of needs or opportunities for change, and for realizing this change (Helfat et al., 2007). The acquisition and exploitation of knowledge through the company's resource base is key to success (Breznik \& Lahovnik, 2016). Currently, it is assumed that DCs are the outcome of three learning processes: experience accumulation, knowledge articulation, and knowledge codification (Zollo and Winter, 2002). Therefore, building DCs requires a lot of organizational search and learning (Katila and Ahuja, 2002) to sense and to seize opportunities and to reconfigure resources and capabilities in order to develop HMP.

This leads to our first proposition:

Proposition 1: Dynamic Capabilities influence HMPD. Not only the transformation, but also the sensing and seizing activities of DCs influence HMPD/company performance.

\subsection{The Effect of Corporate Control Style on High Margin Products Development}

Corporate level strategy is the strategy of a set of businesses (Grant, 1995). As an intermediary between businesses, the 'centre' is responsible for planning and allocating resources, and auditing and providing central services (Chandler, 1962). Concerning the centre's influence on the corporate mission, Goold (1987) notes that businesses tend towards 'motherhood'. In these cases, the centre may offer non-distinct generalised missions that do not support a diversified business portfolio or present optimal direction to the SBUs within a portfolio due to differing risk, growth, and profitability factors. The tensions between the direction of a corporate entity controlling a portfolio of SBUs, the opportunism that may appear within the competitive environment, and the measurement of what is deemed effective may be influenced by the CCS. For instance, financial control may consider product development requirements as waste and remove them, while strategic planning may lead managers to ineffectively pursue strategies with negative outcomes (Stacey, 1993). The centre is often unfamiliar with the complexity of the environment surrounding capital requests (Goold, 1987); thus, resource allocation will rely on the business managers' ability to manipulate and subvert the approval process. Investment practicalities, such as the centre's understanding of the past performance of project sponsoring proposals, are key 
(Bower, 2007). The manipulation of ROI is known throughout the organisation and is purposefully discounted as long as there is a sufficient track record (Goold, 1987). The ability to undertake such manipulation depends on the quality of the dynamic managerial capabilities of managerial cognition (Adner and Helfat, 2003), of social capital within a business ( $\mathrm{Li}$ et al, 2008), and of the company-specific and generic human capital possessed by the managers and TMTs (Díaz-Fernández et al., 2015). A lack of adequate dynamic managerial capabilities may impose limits on the SBUs' plans to initiate product development and requires investment with a limited prior track record or within a diverse corporate environment containing SBUs of mixed growth and investment rates. This is further limiting, given that the diversity of a business's portfolio is its key strength (Bower \& Glibert, 2007) in allowing the optimisation of resource allocation.

The reliance on financial payback as a measure of a project's importance may impose a limit on the long term performance of a financially controlled organisation. The cost implications of reallocating resources and the reduced emphasis on a project's fit with the overall strategy of a business typically reduces long term organic growth by decreasing the likelihood of financial setbacks (Goold \& Campbell, 1987). Commitment to new opportunities requires approval based on payback duration and strategy.

High-technology products consist of systems of interdependent components (Teece, 2007) sourced from different SBU's. The emphasis on the SBU coordination necessary for product development in high-velocity environments (Eisenhardt \& Martin, 2000) is driven by CCS (Goold \& Campbell, 1987), affecting its efficacy. Decisions in terms of optimisation, such as rules and routines for ROI (Bower \& Glibert, 2007) and the openness to flexibility at the risk of reduced optimisation must be made acceptable within the CCS. In addition, entrepreneurial activities and the autonomy to pursue innovation, given the uncertainty that is ubiquitous with innovation (Teece et al, 2016), further suggest that CCS is critical in achieving HMPD.

CCS can influence both managerial perceptions of the competitive environment and the subsequent decision making regarding the development of second order competencies (Daneels, 2008). Incentivising managers to excessively mitigate risks and rewards may lead to the identification of high-velocity business environments as lowvelocity ones. This could result in short-term efficiency, but may stifle long-term 
organic growth by reducing the organisation's acceptance of failure, compounding the future managers' abilities to weigh risks and rewards (Daneels, 2008). Further, the acceleration or deceleration of the business environment-either over time or due to changing internal or external factors-may inhibit the incumbent organisation in optimising its HMPD activities. This leads to our second proposition:

Proposition 2: Corporate control style directly influences HMPD through factors such as direction, commitment, coordination, and optimisation.

\subsection{The effect of Corporate Control Style on Dynamic Capabilities Development.}

The interaction between CCS and each element of the DCs tripartite (sensing, seizing, and transforming) is an area worthy of further consideration (Breznik and Lahovnik, 2016). In terms of sensing and shaping, DCs are of particular importance in environments of deep uncertainty with indefinite unknown unknowns (Teece et al, 2016). For organisations operating within multiple industries characterised by differing associated levels of risk and uncertainty, this generates questions as to the investment required, given the associated costs of agility (Teece et al, 2016) and CCS (Goold \& Campbell, 1987).

Product development requires the ability to reconfigure resources (Eisenhardt \& Martin, 2000) including the development of relevant DCs. The exclusion of the development of one or more capabilities may negatively impact others due to interdependencies (Breznik \& Lahovnik, 2016). High technology products consisting of systems of interdependent components (Teece, 2007) may be sourced from different SBUs. CCS defines the requirements in terms of resource allocations, affecting the organisation's ability to reconfigure its capabilities in order for new strategic initiatives to be born (Salvato, 2003). Yet, ROI calculations may fail to account for high technology products from independently managed but interdependent SBUs.

A key implementation of DCs is in the organisation's decisions pertaining to the creation, integration, recombination, and release of resources (Eisenhardt \& Martin, 2000). The allocation of resources based on the project manager's history of success, on the strategic fit of the project, and on the optimisation of project selection will drive DCs and innovation (Bower and Gilbert, 2007). However, whether decisions should be 
made at the business or corporate level remains unclear (Eisenhardt \& Martin, 2000). Still, governance may provoke the development of DCs within the SBU when the latter is subject to "performance controls that can only be achieved through the ruthless elimination of waste activities and costs" (Bowman and Ambrosini, 2003: 294) that may deter expenditure on future orientated activities such as R\&D. Thus, CCS may directly influence the development of DCs (Breznik and Lahovnik, 2016).

Within the CCS environment, managers must define their SBUs' position within a continuum, leaning either towards a lower-velocity environment, which will allow for stable, analytical, and predictable routines, or towards a high-velocity one requiring more experiential and fragile processes with more unpredictable outcomes and mistakes. The performance of organisations within high-velocity environments is directly linked to the management of systemic innovation aimed at combining multiple inventions to create products or services that address customer needs (Helfat, et al., 2007), which will require common managerial control across SBUs to co-ordinate activity, a key factor within strategic CCS (Goold \& Campbell, 1987). Conversely, autonomous innovation - in which individual components can be developed independently with minimal component interdependency-may be possible without SBU co-ordination, but may not provide solutions within high-velocity environments (Teece, 2000).

To summarize, HMPD requires sensing, shaping, seizing, transforming DCs that are influenced by CCS, affecting elements such as resource allocation. Limitations in some capabilities may negatively impact others and reduce the SBUs' capability to implement strategies, including HMPD. This could affect the organisation due to the importance of interdependencies, especially in high-velocity environments (Breznik \& Lahovnik, 2016). This leads to our third proposition:

Proposition 3: CCS influences the ability of the SBU to develop DCs. More specifically: Proposition 3a: CCS regulates the outcome of the relationship between the sensing and shaping aspects of DCs and HMPD through issues such as employment, remuneration and trust.

Proposition 3b: CCS influences the seizing and reconfiguring aspects of DCs through the control of elements such as mission, investment requirements, and strategy. 


\section{Methodology}

\subsection{Research Design}

To contribute to the enhancement of DCs theory, this paper adopts an inductive case study methodology to examine the link between the DCs, CCS and the company's performance (Eisenhardt, 1989; Yin, 2014). Teece et al. (1997) note that DCs are company-specific and unique. This assumption is related to the importance of corporate idiosyncratic path-dependent histories of investments and commitments towards the creation and development of DCs. Conversely, Eisenhardt and Martin (2000) support the existence of cross-company commonalities regarding DCs. However, these authors also observed that there is no such thing as identical cross-company DCs, as such capabilities, although showing common characteristics, are idiosyncratic in their specifics (Barreto, 2010). Following this perspective and an inductive research approach, a qualitative case study research strategy was developed, focussing on an indepth analysis of a single case study (Eisenhardt,1989; Eriksson et al, 2014, Yin, 2014). A semi-structured interview data collection method was applied to enable the understanding of the sample narratives used to identify the link between DCs, CCS, and HMPD. The semi-structured interviews enabled the interviewer to follow themes as they were mainly pre-determined following the literature review.

The semi-structured interview questionnaire was made up of 18 questions in two sections. The first, in which issues surrounding HMPD were explored, focussed on the company as a whole. Specifically, it explored elements such as strategic orientation, evaluation, organizational communication, co-ordination, HQs influence, environmental rate of change, and risks. The second section centred on the HMPD narratives themselves, and explored their alignment with DCs (the questions were related to sensing, seizing, and transforming activities, routines, and processes, knowledge and learning diffusion) and CCS (investment decisions, investment management, SBU communication and coordination, performance measures, resource allocation, direction, optimization, flexibility, strategic fit, HRM strategy, etc.). We investigated negative cases and counterfactual questioning. In alignment with similar studies, HMPD examples were referenced and alternatives allowed if required, (Breznik \& Lahovnik, 2016). 
The case study organisation was a large international company in the energy and telecom sector with sales exceeding $€ 7$ billion and employing 20,000 workers across 50 countries. The great significance of better understanding company-level sources of competitive advantage is based upon the recognition that performance variances between companies are primarily attributable to their SBUs (Teece, 2007). For this research, the Telecom SBU was investigated due to its long history of HMPD, high product integrated margin, and short product lifecycle factors, which indicated that it operates in a high-velocity environment (Eisenhardt, 1989). Addressing the call made by Easterby-Smith et al (2009), we aimed to examine the development of DCs and their effects over time by exploring the SBU's long history of HMPD. We looked for the foundations of HMPD in DCs and CCS. Thus, we targeted interviewees who had worked within the innovation function of the organisation for more than 10 years and those who were employed at senior engineering or senior management level within the hierarchy. We identified nine candidates with the above characteristics and interviewed them all separately.

\section{INSERT TABLE 1 HERE}

Cumulatively, the interviewees had a total of 256 years' experience within the organisation, with an average of 28.4 years each. Six of the interviewees held managing positions within the Innovation function of the organisation (four local and two global managers), while three of them were senior managers (one local and two global managers). Before each interview, an informal conversation took place to ensure the interviewees in regard to confidentiality. Prior to the interviews, eight HMPD examples were identified to be used as reference based on their contribution or integrated margin within the organisation. The data collection started with a pre-prepared data coding system in order to test propositions. Negative examples and counter-factual questions were utilised in order to rigorously test the propositions. A pilot interview with a single participant enabled the data to be re-coded into themes and sub-themes. The process and questions were reviewed; some questions being removed or harmonised. Then, the remaining interviews were conducted over a period of three weeks. Interview duration ranged from 40 to 90 minutes, with an average of 59 minutes, which was aligned with similar studies (Breznik \& Lahovnik, 2016).

Firstly, the senior product development engineers with direct experience in developing solutions were interviewed. These were followed by engineering managers 
who had overseen product developments within the SBU and, lastly, by directors and senior HQ based managers who oversaw multiple geographical locations or SBUs.

The interviews were transcribed for further analysis. NVivo was used to conduct a thematic coding of the empirical data (Braun and Clarke, 2006). The main themes and subthemes were predetermined, while a few new ones emerged while coding. Table 2 lists the major themes and sub-themes and the times when those themes were found.

\section{INSERT TABLE 2 HERE}

\subsection{Concepts of Exploration, Trustworthiness, and Ethical Considerations}

The measurement of CCS was made by identifying planning and control influence indicators (Goold \& Campbell, 1987). Planning influence (business vs corporate) was considered through narrative examples over a 45-year period, as experienced by participants, and HMPD was investigated to outline corporate involvement. As outlined by Goold and Campbell (1987), planning influence questions encompassed organisational structure, review of plans, strategic themes, strategic thrusts, specific suggestions, management overlaps, and allocation of resources. In the same way control influence (flexible, strategic, and tight financial) was investigated through narrative examples. Control influence questions encompassed agreeing objectives, monitoring results, pressures, and incentives.

The participants were encouraged to provide any negative and counter-factual examples. The objective here was not to identify with which CCS the organisation may have identified (Goold and Campbell, 1987), but rather how the elements of these styles interacted with HMPD and whether the organisation embraced one of the main CCSs. Similarly, the micro-foundations and practicalities (Breznik \& Lahovnik, 2016) of the tripartite of DCs were investigated.

The ethical use of the information collected during the process was described in advance while seeking interviewee approval; this fostered a level of personal interviewee assurance that enabled the provision of sensitive and confidential information. The interviewer was conscious of time restrictions, especially in relation to senior personnel. However, this was part of establishing an enabling and credible level of trust that was key to achieving valid responses. The interviewees were asked not to impose personal beliefs or bias. Clarification of examples and of context specific 
colloquialisms was also requested. During the interview process, methods such as clarifying questions were used to ensure response validity. Furthermore, counterfactual and negative cases were explored to ensure credibility.

\section{Analysis and Results}

\subsection{The effect of the development of Dynamic Capabilities on company Performance - High Margin Product Development}

The empirical evidence on the nature of the link between the DCs' sensing, shaping and transforming activities and company performance, measured as HMPD, revealed that SBU completed its environmental scanning with the Headquarters "only focusing on areas that need attention, that aren't meeting targets". The SBU was to sense new HMPD opportunities, as "we know our market best". This was completed through an "undefined process" although HMPD examples demonstrated consistent themes. In almost all examples, HMPDs were the result of the Technical and Key Account Managers' (KAMs) relationships with key customers over a number of decades at both the sales and technical levels. Typically, this relationship would afford insights into technical issues, and development would occur across organisational boundaries. In comparison to education, experience was considered to be "the most important factor" in the organisation's ability to sense new opportunities.

The interviewees also perceived the shaping of opportunities as being key to the organisation's success. Examples included "senior level involvement in global regulatory bodies driving the development of international regulation" in parallel with "product solutions". Implementation was almost entirely completed at the local SBU level, which was perceived as being "beneficial to the rate of development of both products and parallel regulations". A few actionable shaping activity examples were completed by Headquarters. These examples were identified at an early stage as crossing geographic and SBU boundaries, although they were considered to "have issues with direction and strategy".

The SBU management's approach to deciding HMPD prioritisation was: " $60 \%$ immediate sales, $30 \%$ future sales and $10 \%$ let's have a go for 'blue ocean' products". 
The interviewees described the decisions leading to actions to seize R\&D\&I opportunities as based on short term financial requirements. Opportunities were prioritised based on an informal appraisal of volume and margin potential that, in turn, was based on the key decision makers' understanding of customer needs, of the importance of the project to the customer, and of the importance of the customer to the SBU. For this reason, geographically local customers tended to take precedence over affiliate opportunities within the SBU, regardless of profitability.

Most of the exemplar HMPDs were identified as requiring the reconfiguration of equipment, operational processes, personnel, and IT systems in order to seize the opportunity. The informants stated that "Headquarters is key as they control Head Count [departmental personnel numbers], but it is possible to creatively move personnel to achieve results". It was difficult to generalise whether reconfiguring was required before or after the opportunity was seized. Some cases allowed the SBU to complete $R \& D \& I$ activities, present product solutions to the market, and complete reconfiguring activities, once these were required by volume industrialisation. Other cases required the reconfiguring of resources in order to complete even the initial R\&D\&I activities. In all cases, the reconfiguring activities were completed within the local SBU in accordance with the SBU's ROI appraisal or, if required, with the involvement of Headquarters. The interviewees referred to reliance on the "entrepreneurial few" in completing reconfiguring activities and to a lack of process, instead of to general investment appraisal guidelines. In a HMPD example, a concept co-created with a key customer was halted by the Headquarters due to perceived risk. Although the SBU management was directly told by Headquarters: “it won't work, don't develop the product", it was able to complete the development while meeting financial KPIs. This success enabled the SBU to take on further project risks with Headquarters support.

The findings support the first proposition that HMPD is not only affected by DCs reconfiguring activities, but also by sensing, shaping, and seizing ones. Regarding the nature of the link between DCs and company performance measured as HMPD, there is evidence for the existence of a direct link between the two. However, we also find evidence that there are factors, such as CCS, which seem to significantly affect the outcome of this link. 


\subsection{The effect of CCS on HMPD and on the link between DCs and HMPD (performance)}

The interviewees suggested a Motherhood approach to the company's mission statement (Goold \& Campbell, 1987), describing it as "lacking distinction between SBUs or from competitors", "created centrally", and "communicated insufficiently". The interviewees emphasized that "locally, the organisation has a good understanding of customers' requirements" and that "the success of developed products demonstrates our knowledge of market requirements", but that it did not associate with the corporate level as "HQ has limited knowledge of the complexity of products or the local environment".

The organisation was financially focussed, with multiple participants describing as "it's very short term, it's this month, it's this quarter" and as "financially cagey". Meeting short term financial targets was considered "imperative to meet shareholder expectations". However, this financial focus brought up a number of disharmonious narratives in relation to the organisation's values, such as a case in which "management delayed a customer delivery in order to balance monthly sales figures and meet KPIs". However, the organisations' financial focus was perceived as being in some ways beneficial to the SBU management team in "achieving HMPD through permitting local optimisation and freedom", as long as the "Management Plan" KPIs defining short term financial targets were sufficiently met.

Negative examples in which the organisation had acted in accordance with a long term strategy included the production of off-shore production bases and testing facilities that had not met strict investment appraisal requirements. All negative cases involved investments that were beyond the SBU's investment thresholds, and therefore required HQ approval. All were specific to the performance of individual SBU and, were "initiated within the last five years and aligned with generalised SBU long term strategy"; for instance, to reduce cost base or deliver specialised testing in a geographical market; thus supporting the second proposition that CCS influences coordination and optimisation (Goold \& Campbell, 1987).

Locally managed stable processes allowed SBU managers to identify the need for and request support from Headquarters. The support was "mainly financial, as HR does not 
provide other kind of support to employees or managers". The requirement for support was due to a requirement for capital investment that was beyond the SBU's threshold. Only once in the last 45 years had a project request been met with support in the form of additional personnel; this was perceived as being due to "the SBU being forecast to miss financial targets".

Although the organisation provided a number of examples of SBU specific investments, there were limited ones of cross SBU investment. Further, SBU level decision making had resulted in suboptimal outcomes. In one example, "an SBU that supplied fundamental product parts withdrew products in order to maximise its internal profitability, resulting in a number of HMP from interdependent SBUs having to be withdrawn from the market". In another case, "a factory relocation purposefully relocated equipment to an affiliate site due to depreciation levels resulting in the withdrawal of a range of products with future growth potential'. Decision making was consistently linked to SBU short term financial KPIs such as "contribution margin" and not to the product integrated margin or to the strategic direction of the company. In addition, all HMPD examples had been produced by between two and four interdependent SBUs and "multiple integrated technology platforms", in line with high technology product theory (Teece, 2009).

Aspects of a Headquarters financial CCS that manages interdependent SBU investments involve the separate optimisation of SBUs, which may have complex or unknown effects on HMPD. The evidence provides support for the second proposition; i.e., that CCS influences the development of HMPD factors such as direction, coordination, optimisation, and investment.

\subsection{The effect of Corporate Control Style on the Development of Dynamic Capabilities.}

Resource allocation was based on ROI appraisal and was considered a purely financial aspect. This resulted in SBUs facing limitations in their seizing and reconfiguring activities if they did not meet requirements, with senior SBU management stating "resolving our weaknesses is outside of our capability, we don't hold the purse strings to drive resource" and "HQ has no input and little influence into reconfiguring in order to seize opportunities. HQ mostly involve in head count. Other issues would not involve 
$H Q$. Otherwise, if the local business or SBU was not meeting financial goals, external involvement may occur. Technology transfer would also involve $H Q$ ”. Headquarters had limited familiarity with the environment, exasperating situations in which investment appraisal would not meet ROI requirements in terms of short term revenue. The processes for investment appraisal were completed at the local SBU level and considered to be subject to stringent ROI NPV and payback rules: "We wouldn't get anything approved unless we manipulated the rules". Over the past two decades, it had become more difficult to get approval for investment and the SBU's authority had declined, suggesting a style shift towards a financial focus. "HMPDs were vital to the long-term financial success of the organisation" and the "engineering functions contribution to the success of the company can be greater if we are able to somehow persuade the company that we can do more; given more tools, more resources, more money, we can deliver more”.

The interviewees agreed that technological knowledge resided in a "small number of experts" and was not dispersed "due to a number of factors such as [terrible] cross functional communication, training and investment in people". One senior employee stated that "if three people were moved, it would have catastrophic results". Although a number of counter-examples show that this had been identified as a risk within the organisation, a bi-modal age distribution suggests that, for some time, it had not been considered of high importance; further, it was suggested that it may have been considered waste within the financial control environment.

No negative examples of failure were identified. The SBU's reports to Headquarters allowed transparency and the latter understood the inevitability of failure in R\&D\&I activities. Risk management had become a prominent feature within the last two decades; however, increasingly, only projects with immediate order potential were backed with a "develop, launch, sell" approach, in a growing contrast to historical examples. It was felt that this approach: "leaves high risk, high reward opportunities to competitors". A significant percentage of HMPDs involved managing the risk that the solution would not meet customer expectations, which would negatively influence customer perception and future business. Interdepartmental conflict occurred due to opposing objectives and KPIs. The procurement and engineering functions' requirements for new material approval contradicted the ability of logistic managers to meet KPIs based on minimising inventory and no allowance was made for this activity, 
informants described this as creating a "conflict approach to motivation", generating a zero-sum environment.

|The reconfiguring activities were "completed at a SBU level and success was based on management ability". Any capital requirements were appraised through Headquarters-defined guidelines and those exceeding the SBU's limits required Headquarters involvement, supporting the proposition of influence. The employee development and reward systems were "driven at SBU level"; however, when asked how the Headquarters rewarded successful HMPDs activities, the informants stated: "it doesn't seem to". Headquarters-driven appraisal processes were viewed as "stale" and to "have shown limited results". The reward systems were considered "dependent on the manager and the motivation of the employee", "mostly coming from management feedback", or even not required as the activities were viewed as being "part of people's job".

The evidence indicates that CCS indirectly influences the sensing and shaping aspects of DCs through factors such as employment, remuneration, and trust. Further CCS can be seen to influence the seizing and reconfiguring aspects of DCs through investment, risk management, and strategy factors. The development of DCs is affected by the HQ's control-related decisions - such as those relating to the level of autonomy of the SBU-and support provided. The link between DCs and HMPD seems also to be affected by the CCS. Indeed, financial CCS was found to have both a positive and a negative influence on the development of DCs.

\section{Discussion and Theoretical Implications}

\subsection{The exploration of the nature and outcome of the link between DCs and performance}

A graphic illustration of the qualitative results is provided below. The findings point at the interdependent nature of DCs, CCS and HMPD. In line with Breznik and Lahovnik (2016), our case study data continues to develop the understanding of DCs as a source of competitive advantage. The narratives strongly highlighted the importance of looking back through time as the environment cannot be viewed statically (Eisenhardt \& Martin, 2000). 


\section{INSERT FIGURE 1 HERE}

Several DCs researchers monitored a positive relationship between DCs and company performance (e.g., Eisenhardt and Martin, 2000; Stadler et al, 2013), others evidenced either insignificant (Zott, 2003) or negative effects (e.g., Wilden and Gudergan, 2014; Pezeshkan et al, 2016). A first contribution of this paper is that it not only explored the link between DCs and company performance but it also shed some light on the specific aspects of the mechanism that can be held responsible for the positive or negative outcome of the link. Performance was explored in terms of the development of commercially successful high margin products, since these products have been proven to improve company revenue, market share, market value, and survival (Katila and Ahuja, 2002). We find strong evidence in favour of the existence of a link between DCs and HMPD-company performance. The outcome of this link seems to be positive, supporting the findings of Eisenhardt and Martin (2000) and Stadler et al (2013). However, how positive such outcome is will depend, among others, on the company's decision-making mechanisms, as a reflection of the CCS it has adopted.

We also uncovered evidence pertaining to the nature of this link. Although early work had assumed the link to be direct (e.g., Teece and Pisano, 1994), it has recently been presented as being indirect, implying that DCs affect performance through the unique resource and capability configurations they develop (e.g., Zollo and Winter, 2002). Our findings unravelled both the direct and indirect regulating influences on DCs and on their link to company performance. The HQ's CCS seems to directly affect the seizing and reconfiguration of DCs at the business level. At the same time, the outcome of the link between the DCs' sensing and shaping activities and HMPD/performance is regulated by the organization's CCS.

We add to the innovation approach to DCs (Doving and Gooderham, 2008; Lee et al, 2011) by providing evidence that not only the transformation activities of DCs development are linked to HMPD/company performance — as supported by Eisenhardt and Martin (2000) — but that its sensing and shaping activities are also linked to HMPD and therefore to company performance. In describing the nature of DCs, Eisenhardt and Martin (2000) and Ambrosini and Bowman, (2009), see them as either particular and recognizable or comprising processes (Teece et al., 1997) that may integrate or reconfigure resources. These processes are believed to be structured as echelons including both the organisational and managerial processes ones designed to identify 
needs or opportunities for change, and to realise this change (Helfat et al., 2007). We saw that CCS affects each aspect of DCs in their effort to achieve HMPD. We did not find any evidence of whether or not the tripartite of DCs is undertaken in a proposed order. In those cases involving technological or regulatory change, a company may need to transform in order to seize. We find that the seizing activity was required either preliminarily, in parallel to, or in the wake of the reconfiguration of personnel, equipment, operational processes, and IT system resources.

We also find that these processes were established at the business level. The headquarters were mostly concerned about the SBU's returns, and did not generally interfere in how these returns were generated. Systemic innovation (Helfat et al., 2007) was identified in HMPD, although the prevalence of common managerial control in coordinating activities across SBUs was not perceived by interviewees and was not aligned with financial CCS (Goold \& Campbell, 1987). Alternative contractual mechanisms for co-ordination (Teece, 1980) were also not identified. The findings indicate that the financial CCS provided a positive feedback loop for inter SBU innovation, suggesting that systemic innovation may be therefore achieved by means of a muddling-through approach. Further, DCs relate to decisions pertaining to the creation, integration, recombination, and release of resources (Eisenhardt \& Martin, 2000); however, it is obvious that CCS influences the practicality of decisions affecting resources and therefore DCs may be affected by a lack of decision-making.

The acquisition and exploitation of knowledge through corporate resource bases is key to success (Breznik \& Lahovnik, 2016). Actually, it is assumed that DCs are the outcome of three learning processes: experience accumulation, knowledge articulation, and knowledge codification (Zollo and Winter, 2002). Therefore, the building of DCs requires much organizational search and learning (Katila and Ahuja, 2002) to sense and to seize opportunities and to reconfigure resources and capabilities in order to develop HMPs. Our findings show that, although knowledge and experience were considered important for the development of DCs and HMPs they were not viewed as being as important as addressing the major customers' evolving needs. 


\subsection{The exploration of the antecedents and micro-foundations of DCs through an examination of the interplay between CCS (corporate level strategy) and the development of DCs at the business level}

Adding to the stream of the antecedents and micro-foundations of DCs (Teece, 2007; Erikson et al, 2014), we find significant evidence of the effect corporate governance/control have on them. Our evidence brings forward the interplay between CCS and the development of DCs at the business level (Breznik et al, 2016; Eriksson et al, 2014). Looking back at the last three decades of the company's operation, we find that the CCS was not static but, rather, dynamic. There is evidence that, over the last two decades, the CCS had progressed towards financial control, but is now changing back towards a more strategic CCS. This was made evident by reduced SBU autonomy, an antecedent of transformation (Teece, 2007), and SBU investment limits without HQ intervention. As Goold and Campbell (1987) noted, the CEO and management team are key to the adoption of a style; when asked, the interviewees highlighted that any expected change in management may change aspects of the CCS.

We find that CCS may lead to sub-optimal HMPD/performance by reducing the possible paths of DCs development. Given that persistent high performance in highvelocity environments is driven by a succession of temporary advantages derived from the development of new products (Eisenhardt \& Martin, 2000), this effect could be considered a compound one, as reduced path availability leads to a reduced future position, leaving fewer future path possibilities. The interviewees suggested that the financial CCS enabled the autonomous development of products (Goold \& Campbell, 1987), and that those examples in which the HQ had provided support, services, or central management had suffered from the latter's lack of understanding of the complexity of the SBU or of the local business. In highly complex industries, a financial CCS provides a more entrepreneurial approach to HMPD.

Any difficulties in appraising resource requests stemming from the interdependencies found in high technology products and from the complexity of SBU markets were a major issue that was limited by the adopted CCS. While a CCS attempts to limit financial risk, it may put an organisation under increased threat from deep uncertainty, again requiring an empowered entrepreneurial management (Teece et al, 2016), which is in line with Bower and Glibert (2007). Further, this contributes to Bowman and Ambrosini's (2003) integration of DCs with corporate level strategies. 
Teece (2007) notes that sensing relates to the individual's capacities and organisational processes connected to uncovering opportunities, while the antecedents of seizing mirror the choice of product architectures and business models, organisational boundaries, decision-making protocols, and the building of loyalty among employees. The antecedents of reconfiguration concern decentralisation, cospecialisation, organizational structure, and knowledge management (Erikson et al, 2014). We find that CCS affects the strenght of sensing and shaping activities by affecting the way in which an organisation makes decisions related to employment (through renumeration), rewards (and therefore employee turnover), mentorship and coaching, networking, and to the building of managerial-employee trust, which, although having been linked to succesfull HMPD, present difficulties in being quantified in terms of ROI (Breznik \& Lahovnik, 2016). Findings identified the importance of sensing, which was completed by senior managers with extensive experience and strong, interdependent relationships with customers across muiltiple levels (Felin \& Powell, 2016). Less experienced personnel may display a reduced relationship between sensing and HMPD. Furthermore, elements of a financial CCS mitigated the SBU level management's ability to effectively protect against the decline of key DCs activities (Michailova and Zhan, 2014; Breznik and Lahovnik, 2016). Adding to Teece's (2007) recognized antecedents of seizing, we identify seizing as being dependent upon corporate CCS, but also upon resource limitations, managerial initiatives, and experimentation. The reconfiguring of equipment, processes, personnel, and IT systems was required within an HQ-determined SBU ROI appraisal process or in conjunction with HQ in order to seize HMPD opportunities. ROI requirements, as defined by HQ, may not allow the SBU to deliver its seizing and reconfiguring activities in a timely and efficent manner, while a CCS that focusses on optimisation over flexibility may not allow risk, failure, and uncertainty (Teece et al, 2016). By setting unclear mission statements and competing departmental KPIs, an organisation may fail to organise itself to deliver seizing and reconfiguring activities. These factors can be exasperated within high-velocity enviroments in which beaucratic features slow the rate of HMPD. Investments in high-technology products consisting of systems of interdependent components created across multiple SBUs are difficult to quantify in ROI routines developed for separately managed SBUs (Teece, 2007) due to the rate of change of products, customers, and regulations (Eisenhardt \& Martin, 2000). 


\subsection{Surge and Lurch Events: an Indicator for the Management of Dynamic Capabilities}

High-velocity environments (Eisenhardt \& Bourgeois, 1988) refer to those that are subject to rapid and discontinuous changes in multiple dimensions, such as demand, competitors, technology, and regulation. However, we claim that industries do not operate in a state of perpetual and consistent high velocity over extended periods of time. Within an industry, a surge in velocity may be caused by a disruptive technology, a new application, or a significant demand-altering regulation. Environmental velocity may slow naturally over time due to increasing barriers such as cost requirements for technology, reduced customer demand, or the availability of substitutes. In the case of the Telecom industry we investigated, the initial invention of the technology in the " 70 s and its swift advancement for commercial use created a high velocity environment. This then slowed as customers, regulations, and products became standardised and entrenched. As the velocity of an environment decreases, the value of DCs also decreases relative to the value of technical capabilities (TCs). Further, as the value that an organisation places on TCs increases, the drive for efficiency negatively influences the antecedents of DCs (remuneration, coaching, and reward). However, events (such as a disruptive new technology, a new regulation, a new powerful competitor, or a change in customer requirements) will again change the velocity of these environments. Figure 2 illustrates the impact of rapid positive or negative changes in environmental velocity on the development of DCs in high-velocity environments.

\section{INSERT FIGURE 2 HERE}

In figure 2, the dash line represents customers, regulations, and products. It begins relatively low and moves into a high position. Where the line is horizontal, the environment is stable and presents little change. For instance, at the (1) position, there is a certain amount of customers, regulations, products. This increases at a standard rate/time for a set period (2) until it stabilises again (3) at another certain amount of customers and regulations. As the dash-line moves from one stable position to the final one, there is an increase and decrease in velocity - this is represented by the black line. The black line in the high position represents high velocity. 
In the Telecom industry, an example would be the move towards "fibre to the home". This event represents a change from stable customers (i.e., from just provider $\mathrm{X}$ to multiple carriers), stable regulations/products (from just backbone optical products to needing products and regulations for "fibre to the home" applications). In these cases, the industry moves from one velocity to another. In turn, the importance and value of DCs will also change. This is not a sudden change, as an event (such as those listed above) will cause an acceleration of environmental factors (the dotted-line) and this acceleration will be seen as an increase in velocity. This is represented as the third derivate of the environmental factors. So, from (1) to (2), the following happens: 1) a stable environment (TCs are more prevalent); 2) a surge event (grey box); 3) the number of customers, products, regulations increases; $3 \mathrm{a}$ ) they increase at a certain rate (blackline-velocity) 3b) the rate at which they increase is initially high, it is not increasing and then it is (dotted-line); 4) either a lurch event occurs or the initial surge event loses momentum (grey-box); 4a) the number of customers, regulations, products is still increasing but at a stable rate; $4 \mathrm{~b}$ ) this is rapid change-high velocity environment (although it is not rapid AND discontinuous).

In this environment, DCs become more prevalent as discussed. Managers should spot such surge and lurch events and act in ways which either promote or diminish DCs: in high velocity environments, organisations need DCs; in low velocity environments, they need TCs. Surge events pose the most risk to sustainability, i.e., the 3rd derivative events that alter uniformity in environmental factors such as customer, products, and regulations. Failing to sense a net positive effect surge event and to reconfigure DCs may limit sustainability through reduced product differentiation. Failing to sense a net negative effect lurch event causing the decrease in the rate of change of customers, products, and regulations may result in a growing cost base and uncompetitive market propositions.

Being aware of the impact of surge and lurch events within an industry may allow the incumbent organisation to become hyper-aware of costs or benefits. Organisations that are on the financial control side of the CCS spectrum are less likely to react favourably to surge events in a timely manner as they are, by definition, reviewing past performance. This is why surge and lurch events are so dangerous. Over time, organisations may reduce their DCs as the environment becomes stable. Then, if something suddenly changes in their environment, they must develop DCs. Findings 
show that events such as the "Dot com bubble" had "left them holding the baby", with aggressive investment prior to the event unlikely to meet payback forecasts. The history of such events was deemed to "scar" the organisation and lower future risk tolerance. By attempting to mitigate the risk of financial loss deriving from these lurch events, an organisation also prevents itself from fully optimising its position, market offerings, and profitability in relation to future surge events. A change in the position of an operating environment in terms of demand, competitors, and technology may be the most difficult to perceive and yet the most time sensitive in its implementation.

\subsection{DCs building, antecedents and aftereffects in developed and emerging markets}

In this paper, we find that innovation and DCs development are sources of competitive advantage not only for EMNEs (Williamson, 2015), but also for MNEs originating from developed markets. Kumar and Yakhlaf (2014) examine the case of the building of DCs in an Indian born-global. In their work, they find that DCs are developed as an aftereffect of experiential and deliberate learning processes. They find evidence in support of a company's competitive position being enhanced through the establishment of an operational links system suited to enable organisational learning and knowledge transfer across markets and regions. In our research, there is evidence of a company using its prior experience and learning to develop HMP. However, this is a process that takes place at the SBU level, and the diffusion of knowledge is not a high priority. What is considered more important is to establish strong relationships with strong customers - exactly as in the case of emerging markets (Williamson, 2015) - and to keep the company agile enough to respond to their needs. Looking at emerging economies, Zhou and Li (2010) also highlight the significance of thoroughly understanding customers thoroughly, as they find that a focus on customers and technology positively affects the adaptive capability of a company, as we do in the developed market context.

The importance of communication for knowledge creation and the successful development of DCs in emerging markets, suggested by Hong et al (2008), has been found important by this paper as well. Specifically, we find that technological knowledge is not dispersed "due to a number of factors such as [terrible] cross functional communication, training and investment in people". This result relates to the 
CCS of the organization, as such elements were not considered of high importance or may have even been considered waste within the financial control environment.

As Dong et al. (2016) reveal while exploring the building of DCs in China, we also find that both the macro-level coevolution between the environment and a companyas in the case of surge and lurch events - and the micro-level coevolution within the company - such as that that due to previous experiences of HMPD-enhance the building of a company's knowledge capability and either lead or inhibit its development of DCs. The importance of market dynamics in the evolution of DCs in emerging markets is also supported by Zhou and Li (2010).

Regarding strategic flexibility, defined as the DC that enables companies to rapidly and successfully reconfigure and reallocate resources and capabilities to respond to environmental changes (Sanchez, 1995), we find that it is heavily affected by a company's CCS, regulating its effect on performance. Conversely, looking at the context of emerging markets, Yang et al (2015) find that institutional support moderates the effects of strategic flexibility on company performance. As for the role of the corporate level manager, our findings agree with those of Ludwig and Pemberton (2011), who find that sensing does not easily happen at the corporate level. We find that, although affected by the CCS, the shaping and reconfiguration activities of the building of DCs also seem to take place at the business level.

\section{Managerial Implications, Limitations, and Further Research}

This paper puts forward a series of managerial implications. Managers should be aware of the existence of a positive link between DCs and company performance. Particularly, not only the transformation activities of DCs, but also their sensing, shaping, and seizing activities are positively related to HMPD and therefore to company performance. However, managers should know that the degree to which DCs positively influence performance will depend on the organization's CCS, as the latter directly affects the seizing and transforming activities of DCs, and also regulates the link between the sensing and shaping activities of DCs and performance. Additionally, managers should note that sensing, seizing, and transforming activities do not take place in any specific order, and that CCS-related decisions have also a direct effect on performance. 
The CCS will influence the development of capabilities. Sensing and shaping activities will be affected by how CCS impacts decisions regarding employment (through remuneration), reward, mentoring and coaching, networking, and the building of trust among management levels. Sensing activities seem to benefit from extensive experience, the diffusion of knowledge, the development of strong and interdependent relationships with customers, good environmental scanning, and participation in regulatory bodies. Seizing activities are again strongly affected by the company's CCS, but also by networking with customers, by resource availability, by in-house politics, and by previous success histories. The transformation of equipment, processes, HR, and IT is again affected by the CCS. A financial CCS focusses on ROI-based decisions or on decisions made in conjunction with the HQ in order to seize opportunities. Transformation is also dependent on resource limitations, organizational boundaries, and initiatives for experimentation/improvement.

Corporate level managers must define their SBU's position within the high/lowvelocity environment spectrum. If their company operates in a high velocity environment, or they predict that it will, they should prioritise investment in more experimental and fragile processes in order to develop DCs. If their company operates in a low-velocity environment, or they predict that it will, they should prioritise investment in more stable, analytical, and predictable routines in order to develop ordinary capabilities. However, managers should note that environments do not operate in a state of perpetual and consistent velocity. Surge events accelerate the environment's velocity, while lurch events reduce it, stabilizing the environment. Managers should spot these surge and lurch events and act in ways which either promote or diminish DCs and TCs: in a high velocity environment, organisations need DCs; in a low velocity one, they need TCs. It is surge events that pose the most risk to sustainability. Failing to sense a net positive effect surge event and to reconfigure DCs may limit sustainability through reduced product differentiation. Failing to sense a net negative effect lurch event that causes a decrease in the rate of change of customers, products, and regulations may result in a growing cost base and uncompetitive market propositions.

As for the limitations of the research, a single case may not allow for the wide generalizability and transferability of the results (Eriksson et al, 2014) across other organisations and industries. However, the investigation supports links between 
established theoretical models that should be further explored quantitatively. As discussed earlier, the investigation attempted to fully mitigate the risks involved in a case study research. Response-bias was mitigated through direct interview guidance and the collection of multiple narratives. This paper has not provided an exhaustive overview of the manner in which CCS and DCs are related-further quantitative research is required to fully characterise their interaction-however, it has evidenced the existence of interdependencies. 


\section{References}

Adner, R., and C.E.Helfat. 2003. Corporate effects and dynamic managerial capabilities. Strategic management journal, 24(10), 1011-1025.

Ambrosini, V., and C.Bowman. 2009. What are dynamic capabilities and are they a useful construct in strategic management? International Journal of Management Reviews, 11(1), 29-49.

Arend, RJ., and P.Bromiley. 2009. Assessing the dynamic capabilities view: spare change, everyone?. Strategic Organization, 7(1): 75-90.

Barreto, I. 2010. Dynamic capabilities: A review of past research and an agenda for the future. Journal of management, 36(1), pp.256-280.

Bower, J., \& Glibert, C. (2007). How managers everyday decisions create or destroy your companys strategy. Harvard business review, 1-9.

Bowman, C., \& V., A. (2003). How the Resource-based and the Dynamic Capability Views of the Firm Inform Corporate-level Strategy. British Journal of Management, 289-303.

Breznik, L., \& Lahovnik, M. (2016). Dynamic capabilities and competitive advantage: Findings from case studies. Journal of Contemporary Management Issues, 167-185.

Chandler, A. (1962). Strategy and structure : chapters in the history of the American industrial enterprise. Washington, DC: Beard Books.

Dong, A., Garbuio, M., \& Lovallo, D. (2016). Generative Sensing: A design perspective on the microfoundations of sensing capabilites. California Management Review, 97-117.

Eisenhardt, K. (1989). Building Theories from case study research. Academy of Management Review, 532-550.

Eisenhardt, K., \& Bourgeois, L. (1988). Politics of strategic decision making in high velocity environments: Towards a mid range theory. Academy of management journal , 737770 .

Eisenhardt, K., \& Martin, J. (2000). Dynamic capabilties: What are they? Strategic Management Journal , 1105-1121.

Eriksson, T., Nummela, N., \& Saaewenketo, S. (2014). Dynamic capability in a small global factory. International business review, 169-180.

Felin, T., \& Powell, T. (2016). Designing organizations for dynamic capabilites. California management review , 78-96.

Gong, Y. (2003). Subsidiary staffing in international enterprises, agency, resources, and performance. Academy of management journal, 728-739.

Goold, M., \& Campbell, A. (1987). Strategies and styles: The role of the centre in managing diverse corporations. Oxford: Basil Blackwell.

Grant, R. (1995). Contemporary Strategy Analysis. Oxford: Blackwell. 
Helfat, C., Finkelstein, S., Mitchell, W., Peteraf, M., Singh, H., Teece, D., \& S.G., W. (2007). Dynamic capabilities: Understanding strategic change in organisations. Oxford: Blackwell.

Hench, T. (1999). The history of Herman Miller Inc and the nature of emergence . Journal of management, 362-378.

Hung, R., Yang, B., Lien, B., Mclean, G., \& Kuo, Y. (2010). Dynamic capability: Impact of process alignment and organizational learning culture on performance. Journal of World Business, 285-294.

Lambe, P. (2011). The unacknowledged parentage of knowledge management. Journal of knowledge managment, 175-197.

Meyer, K. E., R, M., \& R, N. (2010). Multinational enterprises and local contexts: The opportunities and challenges of muiltiple-embeddedness. Journal of Management Studies, Vol. 48, 235-252.

Michailova, S., \& Zhan, W. (2014). Dynamic capabilities and innovation in MNC subsidiaries. Journal of world business, 576-583.

Mintzberg, H. (1994). The fall and rise of strategic planning. Harvard Business Review, 107114.

Mintzberg, H., \& Waters, J. (1985). Of strategy: deliberate and emergent . Strategic Management Journal, Vol. 6, 257-272.

Moncrieff, J. (1999). Is strategy making a difference. Long Range Planning, Vol. 32 , 273-276.

Nag, R., Hambrick, D., \& Chen, M. (2007). What is strategic management, really? Inductive derivation of a consensus definition of the field. Strategic Management Journal, 935955.

Nonaka, I., \& Teece, D. (2001). Managing industrial knowledge : creation, transfer and utilization. London: Sage Publications.

Penrose, E. (1959). The Theory of the Growth of the firm. Oxford: Oxford University Press.

Porter, M. (1985). Competitve Advantage. New York: The Free Press.

Prahalad, C., \& Hamel, G. (1990). The core competence of the corporation. Harvard business review, 79-91.

Schumpeter, J. (1911). The Theory of Economic Development: An Inquriy into Profits, Captial, Credit, Interest, and the Business Cycle. New Brunswick, NJ: Transaction Publishers .

Schumpeter, J. (1942). Capitalism, Socialism, and Democracy. New York: Harper.

Showstack, G. L. (1988). Limitation is the mother of innovation. Journal of Business Strategy, Vol. 9, 52-52.

Sirmon, D., Hitt, M., Arregle, J., \& Campbell, J. (2010). The dynamic interplau of capability strengths and weaknesses: Investigating the bases on temporary competitive advantage . Strategic Management Journal, 1386-1409. 
Stacey, R. (1993). Strategy as order emerging from chaos. Long Range Planning Vol. 26, 3-9.

Stacey, R. (2011). Strategic Management and Organisational Dynamics: The challenge of complexity to ways of thinking about organisations. Harlow: Financial Times Prentice Hall .

Teece, D. (1980). Economics of scope and the scope of the enterprise. Journal of economic behavior and organisation, 29-44.

Teece, D. (1986). Profiting from technological innovation. Research Policy, 285-305.

Teece, D. (2000). Managing Intellectual Capital: Organizational, Strategic, and Policy Dimensions. Oxford: Oxford University Press.

Teece, D. (2007). Explicating Dynamic Capabilities: The Nature and Microfoundations of (Sustainable) Enterprise Performance. Strategic Management Journal, 1319-1350.

Teece, D. (2007). EXPLICATING DYNAMIC CAPABILITIES: THE NATURE AND MICROFOUNDATIONS OF (SUSTAINABLE) ENTERPRISE PERFORMANCE.

Teece, D. (2009). Explicating dynamic capabilities: The nature and microfoundations of (sustainable) enterprise development. Strategic Management Journal, 1319-1350.

Teece, D. (2014). The foundations of enterprise performance: Dynamic and ordinary capabilites in an (economic) theory of firms. The academy of management perspectives, 328-352.

Teece, D., \& Augier, M. (2007). Dynamic capabilities and muiltinational enterprise: Penrosean insights and omissions. Management International Review, 175-192.

Teece, D., \& Pisano, G. (1994). The Dynamic Capabilities of Firms: An Introduction. Industrial and Corporate Change, 537-556.

Teece, D., Peteraf, M., \& Leih, S. (2016). Dynamic capabilities and organisational agility: Risk, Uncertainty, and Strategy in the innovation economy. California Management Review, 13-35.

Teece, D., Pisano, G., \& Shuen, A. (1997). Dynamic capabilities and strategic management. Strategic Management Journal, 509-533.

Zhou, K.Z., and C.B. Li 2010. How strategic orientations influence the building of dynamic capability in emerging economies. Journal of Business Research, 63(3), 224-231.

Zollo, M., and S.G Winter. 2002. Deliberate learning and the evolution of dynamic capabilities. Organization Science, 13(3), 339-351.

Zott, C.2003. Dynamic capabilities and the emergence of intra-industry differential firm performance: insights from a simulation study. Strategic Management Journal, 24 (2), 97-125.

\section{FIGURE 1}




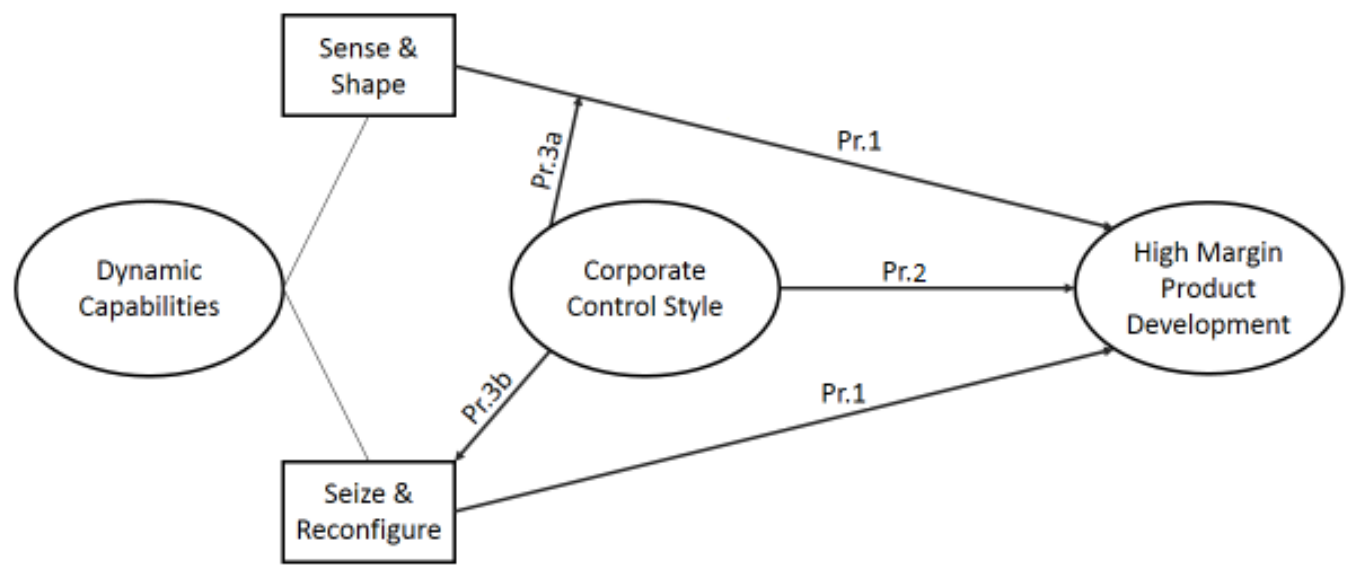

Figure 1: Graphic illustration of the qualitative findings 
FIGURE 2

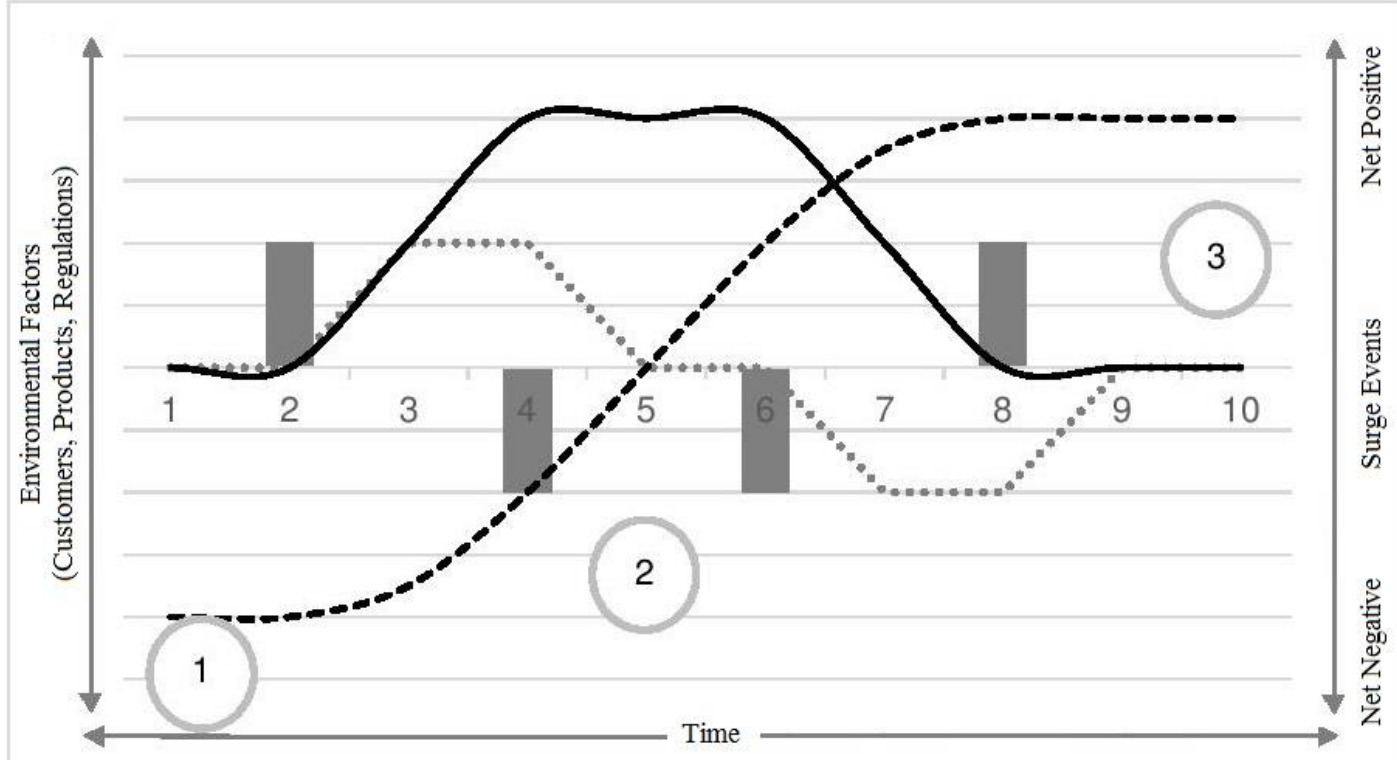

Positive effect "Surge" and Negative effect "Lurch" Events

Enviromental Acceleration

— Enviromental Velocity (Eisenhardt \& Bourgeois, 1988)

----Customers, Regulations, Products

1. Stable Customers, Products. Low DC precedent (High TC precedent)

2. Rapid change in Customers etc. High Velocity environment (though constant), High DC precedent (Low TC precedent)

3. Return to stable Customers, Products. Return to Low DC precedent

Figure 2: "Surge" and "Lurch" events and their relative effect on Customers, Regulations, and Product Uniformity. 
TABLE 1

\begin{tabular}{|l|l|l|l|l|l|}
\hline Interviewee & $\begin{array}{l}\text { Position in the Company/ } \\
\text { Corporate Title }\end{array}$ & Age & $\begin{array}{l}\text { No of years } \\
\text { working in the } \\
\text { company }\end{array}$ & $\begin{array}{l}\text { Work-Base } \\
\text { Location }\end{array}$ & $\begin{array}{l}\text { Locations } \\
\text { they oversaw }\end{array}$ \\
\hline 1 & Chief Engineering Manager of the SBU & 59 & 35 & UK & UK \\
\hline 2 & $\begin{array}{l}\text { Engineering Process Development } \\
\text { Manager }\end{array}$ & 52 & 24 & UK & UK \\
\hline 3 & Senior Design Engineer & 42 & 17 & Spain & UK \\
\hline 4 & Company's Director & 50 & 25 & Italy & Global \\
\hline 5 & Engineering Director & 55 & 35 & UK & UK \\
\hline 6 & Senior Design Engineer & 64 & 45 & UK & UK \\
\hline 7 & Key Account Manager & 35 & 15 & UK & EMEA \\
\hline 8 & Principal Application Engineer & 63 & 45 & UK & Global \\
\hline 9 & Senior Design Engineer & 35 & 15 & UK & UK \\
\hline Table 1: The profile of the Interviewees & & & & \\
\hline
\end{tabular}

TABLE 2

\begin{tabular}{|c|c|c|c|c|c|}
\hline HMPD & \multicolumn{3}{|c|}{ DC } & CCS & Environmental \\
\hline & Sensing & Seizing & $\begin{array}{l}\text { Shaping } \\
\text { Transforming }\end{array}$ & & \\
\hline $\begin{array}{l}\text { Complexity } \\
\text { (S.6,R.6) } \\
\text { Customer } \\
\text { Related } \\
\text { (S.2,R.3) }\end{array}$ & 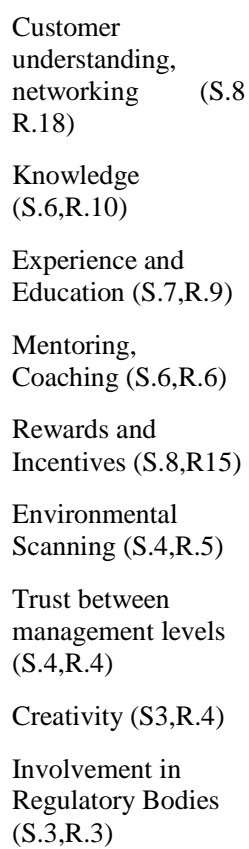 & $\begin{array}{l}\text { Decision-making } \\
\text { Protocol } \\
\text { (S.7,R.16) } \\
\text { Customer-focused } \\
\text { seizing (S.4,R.8) } \\
\text { Support from HQ } \\
\text { (S.4,R.4) } \\
\text { Resources } \\
\text { Availability } \\
\text { (S.3,R4) } \\
\text { Market Focus } \\
\text { (S.3,R.3) } \\
\text { Strategic } \\
\text { Importance } \\
\text { (S.2,R.3) } \\
\text { Previous Success } \\
\text { (S.2,R.2) } \\
\text { In-house politics } \\
\text { (S.1,R.1) }\end{array}$ & $\begin{array}{l}\text { [Equipment, } \\
\text { Processes, HR, IT] } \\
\text { CCS Driven (S.4 } \\
\text { R.5) } \\
\text { Dependent on } \\
\text { resource } \\
\text { limitations (S.2 } \\
\text { R.3) } \\
\text { Managerial } \\
\text { Initiatives (S1.R2) } \\
\text { Organizational } \\
\text { Boundaries } \\
\text { (S.1,R1) } \\
\text { Experimentation/ } \\
\text { Improvement } \\
\text { (S.1,R.1) }\end{array}$ & $\begin{array}{l}\text { Strategic } \\
\text { Orientation and } \\
\text { Long-Term } \\
\text { Objectives } \\
\text { (S.8,R.31) } \\
\text { Communication } \\
\text { (S.7,R.18) } \\
\text { Coordination } \\
\text { and Resource } \\
\text { Sharing } \\
\text { (S.7,R.17) } \\
\text { Level of } \\
\text { autonomy of the } \\
\text { SBU (S.6,R.16) } \\
\text { Support from } \\
\text { the HQ } \\
\text { Provided } \\
\text { (S.3,R.8) } \\
\text { Familiarity with } \\
\text { the SBUs' } \\
\text { complexity } \\
\text { (S.3,R.4) }\end{array}$ & $\begin{array}{l}\text { Dynamism in } \\
\text { Customers, } \\
\text { Products, } \\
\text { Regulations } \\
\text { (S.8,R.11) }\end{array}$ \\
\hline
\end{tabular}

Table 2: The major themes and sub-themes of the research, number of sources that mentioned them $(\mathrm{S})$, number of times they were referenced $(\mathrm{R})$. 